\title{
Ranking the Presses: Political Scientists' Evaluations of Publisher Quality*
}

\author{
Larry P. Goodson, American University in Cairo \\ Bradford Dillman, Koç University \\ Anil Hira, Tulane University
}

N umerous studies in political science have rated and evaluated various elements of importance to the discipline, including graduate programs, journal quality, and even the contribution of individuals within the discipline itself. ${ }^{1} \mathrm{We}$ could not discover, however, any study evaluating the quality of aca-

Larry P. Goodson is assistant professor of political science at the American University in Cairo. His research focuses on Middle Eastern and Central Asian politics, including forthcoming books The Future of Afghanistan Under the Taliban: Impact of a Collapsed State on Regional Politics (University of Washington Press, 1999) and Democratization and Political Liberalization and Democratization in the Middle East (Sage, 2000).

Bradford Dillman is an assistant professor in the Department of International Relations at Koc University in Istanbul, Turkey. He has also taught at the American University in Cairo (1995-98). His research focuses on the political economy of North Africa, state-business relations in the Maghreb, Euro-Mediterranean relations, and electoral politics in the Middle East. His most recent article, titled "The Political Economy of Structural Adjustment in Tunisia and Algeria since the 1980s," will appear in an upcoming issue of the Journal of North African Studies. He is completing a manuscript on state-business relations in Algeria.

Anil Hira is visiting assistant professor of political science at Tulane University under a joint appointment in the department of political science and the Center for Latin American Studies. He taught at the American University in Cairo during 1997-98. His research focuses on international political economy issues, with an emphasis on Latin America, and includes his book How Ideas Affect Economic Policy in Latin America: Regional, National, and Organizational Perspectives (Greenwood Press, 1999). demic book publishers in political science. Yet, as we have witnessed in tenure and promotion cases, in hiring decisions, in departmental gossip, and at APSA meetings and other professional gatherings, with whom one publishes does matter. One colleague wrote us, "I vividly remember a conversation with a fellow author ... [who] refused to submit a manuscript to certain publishers because they were not prestigious enough. In my experience (about thirty years), there is a decided 'unwritten' hierarchy of publishers, not only in political science, indeed, not only in academia." Another noted, "My general sense is that the pecking order of publishers is quite clear within my subfield (at least between the best and the rest)." If there is a clear hierarchy among publishers, then which presses are viewed by members of the discipline as publishing the highest quality books?

\section{Methodology}

To answer this question, we surveyed a sample of APSA members, asking them to assess the overall quality of political science books published by important presses and imprints. We based our approach on that used by Giles, Mizell, and Patterson in their 1989 assessment of political science journal reputations. The first task was to decide which publishers to include in our survey. We began with two lists provided in earlier issues of PS: Political Science and Politics (Kelaher and Artinian 1992, 1994), "whose criteria for inclusion [were] attendance and exhibits at major academic meetings and advertising in publications such as the American Political Science Review" (Kelaher and Artinian 1994, 84). We added all the publishers that had exhibits at the APSA meetings between 1995 and 1997. Inquiries to our university acquisitions librarians produced a few more publishers and important imprints, and we ultimately developed a master list of over 130 English-language publishers, primarily located in the United States and Britain.

Such a large list certainly would have overwhelmed potential respondents. We whittled it down by eliminating small publishers (less than 10 new political science books in 1997), "niche" publishers (for example, Brassey's, an important publisher of military-related books), and publishers whose primary products were not books and monographs (for example, Carfax). Some respondents in our test sample noted omissions, three of which we subsequently included. We ended up with a list of 65 publishers (29 university presses, 34 commercial presses and imprints, and 2 others). ${ }^{2}$

Respondents were asked to "evaluate the overall quality of each publisher's political science books" by scoring them on a scale of $0-4(0=$ poor, 1 = below average, 2 = average, $3=$ above average, $4=$ excellent). Respondents were also instructed to evaluate only those presses/imprints with which they were familiar; if unfamiliar with a publisher, they were instructed to leave the space next to that publisher's name blank. Space was provided for respondents to list and rate other presses/imprints. ${ }^{3}$ We also asked respondents to list presses 
TABLE 1

\section{Political Scientists' Rankings of Publishers}

\begin{tabular}{|c|c|c|c|c|c|}
\hline Rank & Publisher & Mean & S.D. & Median & Familiarity \\
\hline 1 & Cambridge University Press & 3.72 & 0.48 & 4 & $92.51 \%$ \\
\hline 2 & Princeton University Press & 3.61 & 0.66 & 4 & $80.40 \%$ \\
\hline t3 & Oxford University Press & 3.56 & 0.62 & 4 & $87.61 \%$ \\
\hline t3 & University of Chicago Press & 3.56 & 0.63 & 4 & $86.17 \%$ \\
\hline 5 & Yale University Press & 3.48 & 0.68 & 4 & $80.98 \%$ \\
\hline 6 & Harvard University Press & 3.46 & 0.75 & 4 & $87.03 \%$ \\
\hline 7 & University of California Press & 3.31 & 0.71 & 3 & $81.56 \%$ \\
\hline 8 & Cornell University Press & 3.24 & 0.76 & 3 & $76.37 \%$ \\
\hline 9 & University of Michigan Press & 3.19 & 0.79 & 3 & $70.03 \%$ \\
\hline 10 & MIT Press & 3.09 & 0.74 & 3 & $63.40 \%$ \\
\hline 11 & Stanford University Press & 3.06 & 0.81 & 3 & $60.23 \%$ \\
\hline 12 & Johns Hopkins University Press & 3.05 & 0.68 & 3 & $75.50 \%$ \\
\hline 13 & Brookings Institution & 3.04 & 0.86 & 3 & $84.44 \%$ \\
\hline 14 & Columbia University Press & 3.02 & 0.78 & 3 & $76.37 \%$ \\
\hline 15 & Congressional Quarterly Press & 2.93 & 0.84 & 3 & $71.76 \%$ \\
\hline 16 & Basic Books & 2.81 & 0.80 & 3 & $80.69 \%$ \\
\hline $\mathrm{t} 17$ & W.W. Norton and Company & 2.78 & 0.85 & 3 & $65.13 \%$ \\
\hline $\mathrm{t} 17$ & Blackwell Publishers & 2.78 & 0.80 & 3 & $67.72 \%$ \\
\hline 19 & Routledge & 2.74 & 0.84 & 3 & $70.61 \%$ \\
\hline t20 & Sage Publications, Inc. & 2.71 & 0.88 & 3 & $81.56 \%$ \\
\hline t20 & St. Martin's Press & 2.71 & 0.79 & 3 & $77.52 \%$ \\
\hline 22 & University of North Carolina Press & 2.65 & 0.81 & 3 & $48.70 \%$ \\
\hline t23 & Duke University Press & 2.63 & 0.89 & 3 & $58.21 \%$ \\
\hline t23 & University of Wisconsin Press & 2.63 & 0.74 & 3 & $39.48 \%$ \\
\hline 25 & Penguin Putnam Inc. & 2.61 & 0.86 & 3 & $46.69 \%$ \\
\hline 26 & Westview Press & 2.59 & 0.84 & 3 & $79.54 \%$ \\
\hline 27 & Houghton Mifflin Company & 2.56 & 0.82 & 3 & $63.69 \%$ \\
\hline 28 & Chatham House Publishers & 2.54 & 0.83 & 3 & $74.06 \%$ \\
\hline 29 & New York University Press & 2.51 & 0.81 & 3 & $50.72 \%$ \\
\hline $\mathrm{t} 30$ & University of Pittsburgh Press & 2.50 & 0.76 & 2.5 & $50.43 \%$ \\
\hline t30 & Random House, Inc. & 2.50 & 0.82 & 2 & $61.10 \%$ \\
\hline t30 & Rowman \& Littlefield & 2.50 & 0.82 & 2 & $51.87 \%$ \\
\hline t33 & Indiana University Press & 2.49 & 0.83 & 3 & $47.84 \%$ \\
\hline $\mathrm{t} 33$ & HarperCollins College Publishers & 2.49 & 0.76 & 2 & $67.72 \%$ \\
\hline t35 & Lynne Rienner Publishers & 2.48 & 0.93 & 2 & $57.06 \%$ \\
\hline t35 & Simon and Schuster & 2.48 & 0.77 & 2 & $53.60 \%$ \\
\hline 37 & West Publishing Company & 2.47 & 0.97 & 2 & $36.89 \%$ \\
\hline t38 & Prentice Hall & 2.46 & 0.80 & 2 & $63.98 \%$ \\
\hline t38 & Macmillan & 2.46 & 0.76 & 2 & $63.40 \%$ \\
\hline 40 & State University of New York Press & 2.40 & 0.92 & 2 & $53.03 \%$ \\
\hline 41 & Penn State Press & 2.39 & 0.85 & 2 & $43.80 \%$ \\
\hline 42 & McGraw-Hill, Inc. & 2.37 & 0.81 & 2 & $65.71 \%$ \\
\hline 43 & Longman Publishing Group & 2.35 & 0.83 & 2 & $60.81 \%$ \\
\hline 44 & University of Illinois Press & 2.32 & 0.82 & 2 & $43.52 \%$ \\
\hline 45 & Harcourt Brace College Publishers & 2.31 & 0.81 & 2 & $60.81 \%$ \\
\hline 46 & M.E. Sharpe, Inc. & 2.30 & 0.85 & 2 & $59.37 \%$ \\
\hline 47 & Temple University Press & 2.26 & 0.88 & 2 & $46.11 \%$ \\
\hline 48 & Kluwer & 2.25 & 0.92 & 2 & $33.43 \%$ \\
\hline 49 & University Press of Virginia & 2.16 & 0.87 & 2 & $27.67 \%$ \\
\hline 50 & United States Institute of Peace & 2.14 & 0.81 & 2 & $30.84 \%$ \\
\hline 51 & Allyn \& Bacon & 2.11 & 0.81 & 2 & $47.26 \%$ \\
\hline 52 & Wadsworth Publishing Company & 2.09 & 0.85 & 2 & $38.33 \%$ \\
\hline 53 & Frank Cass Publishers & 2.08 & 0.88 & 2 & $40.92 \%$ \\
\hline 54 & Louisiana State University Press & 2.03 & 0.87 & 2 & $33.72 \%$ \\
\hline 55 & Transaction Publishers & 2.02 & 0.86 & 2 & $44.96 \%$ \\
\hline 56 & University of South Carolina Press & 2.00 & 0.88 & 2 & $29.97 \%$ \\
\hline 57 & D.C. Heath & 1.96 & 0.84 & 2 & $46.40 \%$ \\
\hline 58 & Greenwood Publishing Group & 1.95 & 0.91 & 2 & $63.11 \%$ \\
\hline 59 & University of Missouri Press & 1.91 & 0.81 & 2 & $25.36 \%$ \\
\hline 60 & Nelson-Hall, Inc. & 1.86 & 0.84 & 2 & $29.11 \%$ \\
\hline 61 & University Press of Florida & 1.83 & 0.79 & 2 & $33.72 \%$ \\
\hline 62 & Humanities Press & 1.81 & 0.95 & 2 & $21.61 \%$ \\
\hline 63 & University Press of America & 1.51 & 0.92 & 1.5 & $55.62 \%$ \\
\hline t64 & Markus Weiner Publishers & 1.47 & 1.01 & 1.5 & $10.95 \%$ \\
\hline t64 & Ashgate Publishing Company & 1.47 & 0.95 & 1 & $17.29 \%$ \\
\hline
\end{tabular}

with which they had published books and the press(es) with which they would most like to publish their next book. Finally, data were gathered on each respondent's age, academic rank, academic affiliation (school), and major subfields of interest.

We conducted our survey via cyberspace because of our location in a middle-sized department (15 fulltime faculty) at a U.S.-accredited university in Cairo, Egypt. Most of our respondents were in the United States, and mail service between Egypt and the U.S. is often slow and sometimes erratic. We extracted a random sample of 3435 names from the approximately 14,000 names listed in the 1997-99 APSA Directory of Members $(\approx 24.5 \%)$. Of these 3435 individuals, 1818 listed email addresses in the Directory (52.9\%). We emailed our questionnaire to all of these addresses, 505 of which were bad $(27.8 \%$ of these 1818 addresses were either no longer valid or mistyped in the Directory). Thus, we were left with 1313 apparently valid addresses, which we used as a base figure from which to calculate our response rate. We received over 400 responses, of which 347 provided usable data, giving an apparent response rate of $26.4 \% .^{4}$

We mailed our questionnaires as many as three times. The first mailing went to all 1818 email addresses. All respondents, either good, bad, ${ }^{5}$ or invalid, were purged from our master copy of addresses, and, after the response rate declined, we resent the questionnaire along with a reminder notice to the apparently good addresses from which no response was received. The same procedure was followed once more, with "last reminder" notices sent out. ${ }^{6}$ The entire survey was conducted over a three-week period in May 1998 (although a handful of respondents mailed or emailed their responses back during June and July 1998).

\section{Results}

The major results of our study are presented in Table 1. As expected, major university presses enjoy the highest level of prestige and greatest familiarity. At the top of the list, in 
both average quality score and familiarity, is Cambridge University Press. It also enjoys the lowest standard deviation, indicating that it is quite uniformly respected. It is closely followed, however, by the presses at Princeton, Oxford, Chicago, Yale, and Harvard. The top 14 presses are all university presses, except for the Brookings Institution Press (\#13). Interestingly, the next seven presses are all commercial publishers. Thereafter, university presses and commercial publishing houses or imprints are intermixed, although the bottom four presses are commercial publishers.

Table 1 demonstrates that, while they tend to be correlated strongly, quality and familiarity do not always go hand-in-hand. Certain presses that are ranked high on quality (for example, University of North Carolina Press or University of Wisconsin Press) were not known by more than half of our respondents, while other presses that ranked low on quality were quite well known (for example, Greenwood Publishing Group and McGraw-Hill, Inc.). This can make for an interesting decision for the potential author whose manuscript is of interest to a lower-ranked but better-known publisher as well as a higher-ranked but lesser-known publisher. Table 2 displays the publishers ranked in order of familiarity.

Five basic clusters appear in our analysis. The top 12 presses are all major university publishers, and they rank high in both quality and familiarity. The second cluster contains 10 of the better-known commercial houses of high reputation, such as Routledge. The presses in this cluster rank medium to high in quality and high in familiarity. Presses in the third cluster are characterized by medium-high quality and mediumlow familiarity and include 11 other university presses. The fourth cluster includes some of the larger commercial presses, such as Greenwood and Macmillan. These 15 commercial presses rank medium-low in both quality and familiarity. Finally, the fifth cluster includes 6 university and 10 commercial publishers, generally with small publication lists. These publishers rank low in both quality and familiarity.
TABLE 2

Political Scientists' Familiarity with Publishers

\begin{tabular}{|c|c|c|c|}
\hline Rank & Publisher & $\begin{array}{l}\text { Number of } \\
\text { Responses }\end{array}$ & $\begin{array}{c}\text { Familiarity } \\
\text { (Percentage) }\end{array}$ \\
\hline 1 & Cambridge University Press & 321 & $92.51 \%$ \\
\hline 2 & Oxford University Press & 304 & $87.61 \%$ \\
\hline 3 & Harvard University Press & 302 & $87.03 \%$ \\
\hline 4 & University of Chicago Press & 299 & $86.17 \%$ \\
\hline 5 & Brookings Institution & 293 & $84.44 \%$ \\
\hline t6 & University of California Press & 283 & $81.56 \%$ \\
\hline t6 & Sage Publications, Inc. & 283 & $81.56 \%$ \\
\hline 8 & Yale University Press & 281 & $80.98 \%$ \\
\hline 9 & Basic Books & 280 & $80.69 \%$ \\
\hline 10 & Princeton University Press & 279 & $80.40 \%$ \\
\hline 11 & Westview Press & 276 & $79.54 \%$ \\
\hline 12 & St. Martin's Press & 269 & $77.52 \%$ \\
\hline $\mathrm{t} 13$ & Cornell University Press & 265 & $76.37 \%$ \\
\hline t13 & Columbia University Press & 265 & $76.37 \%$ \\
\hline 15 & Johns Hopkins University Press & 262 & $75.50 \%$ \\
\hline 16 & Chatham House Publishers & 257 & $74.06 \%$ \\
\hline 17 & Congressional Quarterly Press & 249 & $71.76 \%$ \\
\hline 18 & Routledge & 245 & $70.61 \%$ \\
\hline 19 & University of Michigan Press & 243 & $70.03 \%$ \\
\hline t20 & Blackwell Publishers & 234 & $67.72 \%$ \\
\hline t20 & HarperCollins College Publishers & 235 & $67.72 \%$ \\
\hline 22 & McGraw-Hill, Inc. & 228 & $65.71 \%$ \\
\hline 23 & W.W. Norton and Company & 226 & $65.13 \%$ \\
\hline 24 & Prentice Hall & 222 & $63.98 \%$ \\
\hline 25 & Houghton Mifflin Company & 221 & $63.69 \%$ \\
\hline t26 & MIT Press & 220 & $63.40 \%$ \\
\hline t26 & Macmillan & 220 & $63.40 \%$ \\
\hline 28 & Greenwood Publishing Group & 219 & $63.11 \%$ \\
\hline 29 & Random House, Inc. & 212 & $61.10 \%$ \\
\hline 130 & Longman Publishing Group & 211 & $60.81 \%$ \\
\hline t30 & Harcourt Brace College Publishers & 211 & $60.81 \%$ \\
\hline 32 & Stanford University Press & 209 & $60.23 \%$ \\
\hline 33 & M.E. Sharpe, Inc. & 206 & $59.37 \%$ \\
\hline 34 & Duke University Press & 202 & $58.21 \%$ \\
\hline 35 & Lynne Rienner Publishers & 198 & $57.06 \%$ \\
\hline 36 & University Press of America & 193 & $55.62 \%$ \\
\hline 37 & Simon and Schuster & 186 & $53.60 \%$ \\
\hline 38 & State University of New York Press & 184 & $53.03 \%$ \\
\hline 39 & Rowman \& Littlefield & 180 & $51.87 \%$ \\
\hline 40 & New York University Press & 176 & $50.72 \%$ \\
\hline 41 & University of Pittsburgh Press & 175 & $50.43 \%$ \\
\hline 42 & University of North Carolina Press & 169 & $48.70 \%$ \\
\hline 43 & Indiana University Press & 166 & $47.84 \%$ \\
\hline 44 & Allyn \& Bacon & 164 & $47.26 \%$ \\
\hline 45 & Penguin Putman Inc. & 162 & $46.69 \%$ \\
\hline 46 & D.C. Heath & 161 & $46.40 \%$ \\
\hline 47 & Temple University Press & 160 & $46.11 \%$ \\
\hline 48 & Transaction Publishers & 156 & $44.96 \%$ \\
\hline 49 & Penn State Press & 152 & $43.80 \%$ \\
\hline 50 & University of Illinois Press & 151 & $43.52 \%$ \\
\hline 51 & Frank Cass Publishers & 142 & $40.92 \%$ \\
\hline 52 & University of Wisconsin Press & 137 & $39.48 \%$ \\
\hline 53 & Wadsworth Publishing Company & 133 & $38.33 \%$ \\
\hline 54 & West Publishing Company & 128 & $36.89 \%$ \\
\hline t55 & Louisiana State University Press & 117 & $33.72 \%$ \\
\hline t55 & University Press of Florida & 117 & $33.72 \%$ \\
\hline 57 & Kluwer & 116 & $33.43 \%$ \\
\hline 58 & United States Institute of Peace & 107 & $30.84 \%$ \\
\hline 59 & University of South Carolina Press & 104 & $29.97 \%$ \\
\hline 60 & Nelson-Hall, Inc. & 101 & $29.11 \%$ \\
\hline 61 & University Press of Virginia & 96 & $27.67 \%$ \\
\hline 62 & University of Missouri Press & 88 & $25.36 \%$ \\
\hline 63 & Humanities Press & 75 & $21.61 \%$ \\
\hline 64 & Ashgate Publishing Company & 60 & $17.29 \%$ \\
\hline 65 & Markus Weiner Publishers & 38 & $10.95 \%$ \\
\hline
\end{tabular}


Perhaps the most significant issue raised by our respondents was that comparing publishers, presses, and imprints is just not feasible because each aims at different markets and, thus, does different things. Although several divisions can be noted among publishers of political science books, the major one is between university presses and commercial publishers. ${ }^{7}$ Some respondents said that it was not possible to rank these presses on the same scale because the gap in quality was so great. ${ }^{8}$

Our findings suggest, however, that the gap is not that great, at least, not after the top dozen presses are eliminated. It appears, for example, that publishing with Routledge (\#19 quality, \#18 familiarity) or Sage (\#20 quality, \#7 familiarity) should be more career-enhancing than publishing with Temple University Press (\#47 quality, \#47 familiarity) or Louisiana State University Press (\#54 quality, tied for \#55 familiarity).

The overall findings expressed in the above tables appear to be quite robust, at least for the top publishers in our discipline. Analysis of the additional data gathered revealed no significant variations when we controlled for subfield specialization, professional affiliation, or professorial rank. Age does seem to have some impact, primarily in boosting the rankings of some of the nonuniversity publishers, which fare a bit better among respondents under the age of 40. The question "With whom would you like to publish your next book?" clearly reinforced the overall quality rankings. Although there was a tendency for some authors to rank the publisher(s) of their books higher than did respondents who had not published with those publishers, the data set for each publisher was too small for us to derive statistically significant conclusions about this possible skewing effect.

While it would have been illuminating to ask respondents why they rated some presses higher than others, adding such a question would have lengthened the survey significantly. Nevertheless, some respondents offered explanations for their evaluations, normally citing criteria

TABLE 3 Distribution of Responses by Subfield Interest

\begin{tabular}{lcc}
\hline \multicolumn{1}{c}{ Subfield } & Number of responses & Percentage \\
\hline American Politics & 122 & 21.8 \\
Comparative Politics & 131 & 23.4 \\
International Relations & 89 & 15.9 \\
Methodology & 40 & 7.2 \\
Political Theory & 78 & 14.0 \\
Public Administration & 21 & 3.8 \\
Public Law & 22 & 3.9 \\
Public Policy & 56 & 10.0 \\
Total & 559 & 100.0 \\
\hline
\end{tabular}

such as price, stimulation, originality, research orientation, and sense of overall quality. One respondent, who rated some lesser-known, small commercial presses very highly, noted, "Obviously, I am one among a growing group that finds so many of the standard presses disappointing and overrated. Still, I am very much aware that in order to garner the respect of my co-workers in the field, it is necessary to publish in the likes of Oxford." Another rated a press that he had once considered to be "among the very best serious commercial publishers" as poor on the basis of one disappointing book published after the press was purchased by a "schlock mega-firm." Another ranked almost every university press as poor because they "publish too much of limited interest and value." When listing with whom they would like to publish, respondents also revealed varying motivations that did not necessarily relate to quality. One respondent wanted to publish with Oxford "only as a career move," while another wanted Yale "for prestige" but Prentice-Hall "for royalties."

Use of email as the medium for this research provided some clear advantages and disadvantages relative to traditional snail-mail surveys. ${ }^{9}$ An important consideration is whether our use of email introduced bias into our findings. Possible bias could have several dimensions. First, our low response rate could subject our results to nonresponse bias. It is probable, however, that our true response rate was actually higher than it appears-perhaps even much higher-because we suspect that many of our questionnaires never reached their intended respondent. A related concern is whether or not our sample strategy introduced bias into the research. For example, are those political scientists who have joined APSA, have email addresses, and have reported them to APSA for inclusion in the Directory representative of the discipline? Similarly, did we over- or undersample political scientists from certain subfields, such that our findings reflect only the perceptions of political scientists in a particular subfield? An unrepresentative sample could bias results since many presses concentrate their publishing on works in particular subfields.

We cannot state with certainty that our sample is representative of the discipline. Our approach was the simplest form of probability sampling we could devise, but if the membership of the APSA is not representative of the discipline of political science, or if those members reporting email addresses are different in their opinions from those not reporting email addresses, then our sample may not be representative. Likewise, we cannot be certain that our sample has adequately represented the subfields within the discipline, since we do not know how the discipline is divided numerically into subfields, the range of subfields is so great (and growing), and many political scientists have research and teaching interests in more than one subfield. We asked our respondents to indicate their subfield interests by choosing no more than two subfields from eight categories: American politics, comparative politics, interna- 
tional relations, methodology, political theory, public administration, public law, and public policy. The vast majority of our respondents ( 320 of 347 , or $92.2 \%$ ) identified at least one subfield of interest; most chose two. Based on their total responses $(\mathrm{N}=559)$, the listed subfields were represented as shown in Table 3. Given the overall size of our sample and its wide coverage of major subfields within the discipline, we believe that the reported results reflect, at least generally, perceptions of publisher quality held throughout the discipline.

\section{Conclusions}

Our study suggests that there is reputational capital in publishing.
Political scientists associate a certain (and different) value, quality, and/or market niche to books published by Cambridge University Press, Random House, or Westview Press. These "trademarks" have a value of their own, which is why companies seek to purchase known imprints instead of starting new publishing houses and also why editors view prospective authors and their manuscripts in terms of their publisher's list of books. While it is possible that a new publishing house owner could seek to change an imprint's reputation by increasing the quality of the output or occupying a newly emerging niche, this can only be done within bounds lest the existing reputational capital be lost (especially given publishers' limited resources and the need faced by most publishers to remain commercially viable).

The value of a publication trademark represents capital for authors, too, who assume some of the reputation of the houses with which they publish. The trademark may label an author as an "Ivy Leaguer," who occupies stratospheric realms in the reputational hierarchy, or as a "textbook author," whose reputation may be lower (but bank account bigger). Nonetheless, a book high in reputational capital that sells few copies can still be valuable in terms of helping the author gain tenure, get a position at a top university, or sign contracts for future publications that may reach a larger audience. With whom one publishes does matter.

\section{Notes}

\footnotetext{
* We wish to thank the more than 400 members of APSA (including some of the most distinguished and senior members of the discipline) from over 200 departments and organizations in 22 countries who participated in the survey or test sample.

1. Some of the more recent studies include: graduate programs (Jackman and Siverson 1996; Katz and Eagles 1996; Klingemann 1986; Lowery and Silver 1996; Miller, Tien, and Peebler 1996b; National Research Council 1995; Welch and Hibbing 1983), journal quality (Christensen and Sigelman 1985; Garand 1990; Giles, Mizell, and Patterson 1989; Giles and Wright 1975), and contribution of individuals within the discipline (Miller, Tien, and Peebler 1996a; Robey 1982).

2. The acceleration of mergers and acquisition in the publishing industry was also a consideration. Some large commercial publishers have several imprints and subdivisions whose ownerships have changed several times in recent years. For example, D.C. Heath's textbook division has been acquired by Houghton-Mifflin. HarperCollins College Publishers is now owned by Longman, and its textbooks have been relabeled Longman. While we were conducting the survey, Simon and Schuster sold the imprints Allyn \& Bacon, Prentice Hall, Macmillan, and Jossey-Bass to Pearson Plc. Nevertheless, commercial imprint names, areas of specialization, and publication quality tend to remain very stable. Moreover, we believe that most of our colleagues are unaware of the precise ownership changes and retain their perceptions of presses even well after a merger or acquisition.

3. Ultimately, a total of 144 additional presses, imprints, and publishing houses were listed by respondents, but none by more than $10 \%$, which we used as a cutoff for inclusion in the results. The most frequently listed ad-

ditional press was the University of Kansas Press $(\mathrm{n}=12,3.5 \%)$.

4. This method may have produced an oversampling of senior, tenured members of the profession because such individuals are more likely to be members of APSA and work at larger universities that have had email longer. Given that such individuals are more likely to have well-informed opinions about presses than, say, graduate students who are just starting out, we did not view this potentially unrepresentative sampling technique to be problematic.

5. A little less than $0.5 \%$ of our 1313

"good" addresses elicited responses from individuals suffering from "office rage," who apparently would like to kick us out of the discipline for using their email addresses to conduct this survey.

6. Unfortunately, our university server reset itself several times as it was sending out our last reminders, causing approximately 60 individuals to receive the message in triplicate (or worse). This embarrassing glitch was directly and causally correlated with several of the "office rage" cases referred to above.

7. Divisions could also have been drawn between publishers who specialize in textbooks, reference materials, theory, particular subfields, or area studies, to the point of making any broad comparisons virtually impossible.

8. We used one general list for several reasons. Our main purpose in conducting the survey was to compare overall impressions regardless of individual motivations. When one tries to judge the "quality" of a colleague's work in a subfield or on a subject with which one is unfamiliar, the publisher with which it appears is often the de facto basis of one's assessment. Nonetheless, one could still sympathize with a professor who lamented, "The quality of the book itself is so
}

much more important than the quality of the publisher."

9. Five major advantages can be noted: speed, cost, ease of response, ease of following up for corrections or clarifications, and ease of data entry. Five major disadvantages are: lack of certainty over if and how the instrument will be received, incompatibility across multiple email software packages, varying levels of respondent knowledge regarding how to use email software, loss of respondent anonymity, and ease of deletion (also an advantage, depending on your point of view). We are describing targeted email, which has different characteristics and implications from a survey on the World Wide Web, a listserv, or an email discussion group. Putting a survey on a web site would yield more anonymous results and be less threatening to respondents' privacy, but it would not produce a probability sample. A survey on a listserv or email discussion group would be more targeted and probably yield a higher response rate, but would also not produce a probability sample. 


\section{References}

Christensen, James A., and Lee Sigelman. 1985. "Accrediting Knowledge: Journal Stature and Citation Impact in Social Science." Social Science Quarterly 66(December): $964-76$.

Garand, James C. 1990. "An Alternative Interpretation of Recent Political Science Journal Evaluations." PS: Political Science and Politics 23(September): 444-51.

Giles, Micheal W., Francie Mizell, and David Patterson. 1989. "Political Scientists' Journal Evaluations Revisited." PS: Political Science and Politics 22(September): 61317.

, and Gerald C. Wright. 1975. "Political Scientists' Evaluations of Sixty-Three Journals." PS: Political Science and Politics 8(Summer): 254-57.

Jackman, Robert W., and Randolph M. Siverson. 1996. "Rating the Rating: An Analysis of the National Research Council's Appraisal of Political Science Ph.D. Programs." PS: Political Science and Politics 29(June): 155-60.
Katz, Richard S., and Munroe Eagles. 1996. "Ranking Political Science Programs: A View from the Lower Half." PS: Political Science and Politics 29(June): 149-54.

Kelaher, Christopher J., and Edward Artinian. 1992. "How to Find a Publisher in Political Science." PS: Political Science and Politics 25(June): 262-64.

- 1994. "How to Select a Publisher in Political Science." PS: Political Science and Politics 27(March): 84-90.

Klingemann, Hans-Dieter. 1986. "Ranking the Graduate Departments in the 1980s: Toward Objective Qualitative Indicators." PS: Political Science and Politics 19(Summer): 651-61.

Lowery, Robert C., and Brian D. Silver. 1996. "A Rising Tide Lifts All Boats: Political Science Department Reputation and the Reputation of the University." PS: Political Science and Politics 29(June): 161-67.

Miller, Arthur H., Charles Tien, and Andrew
Peebler. 1996a. "The American Political Science Review Hall of Fame: Assessments and Implications for an Evolving Discipline." PS: Political Science and Politics 29(March): 73-83.

- 1996b. "Department Rankings: An Alternative Approach." PS: Political Science and Politics 29(December): 704-17.

National Research Council. 1995. Research Doctorate Programs in the United States: Continuity and Change. Washington, DC: National Academy Press.

Robey, John S. 1982. "Reputations vs. Citations: Who Are the Top Scholars in Political Science?" PS: Political Science and Politics 15(Spring): 199-200.

Welch, Susan, and John R. Hibbing. 1983. "What Do the New Ratings of Political Science Departments Measure?" PS: Political Science and Politics 16(Summer): 53240. 